\title{
Science Academies' Refresher Course in Advances in Chemical Sciences and Sustainable Development
}

\author{
January 12-25, 2015
}

at Department of Chemistry, School of Chemical Sciences and Pharmacy, Central University of Rajasthan, Ajmer

Sponsored by Indian Academy of Sciences, Bangalore, Indian National Science Academy, New Delhi, The National Academy of Sciences, India, Allahabad

A Refresher Course in Advances in Chemical Sciences and Sustainable Development for College/University teachers and research scholars will be organized at the Department of Chemistry, School of Chemical Sciences and Pharmacy, Central University of Rajasthan, Bandarsindri 305 817, Ajmer Dist., Rajasthan for two weeks from 1225 January, 2015. The Course is aimed at teachers teaching at UG/PG level and research scholars. The Course will cover both basic and advanced topics in Chemical Sciences with emphasis on its relevance to sustainable development. College/University teachers having at least a Master's degree in Chemistry/Chemical Engineering are eligible to apply.

Topics: Selected topics in a standard UG/PG level course syllabus will be covered. There will be four modules:

Module 1: Introduction to bioinorganic chemistry, chemical biology and its applications; chemistry of transition metals; organometallic chemistry and catalysis; organochalocogen chemistry; metallophilic interactions.

Module 2: Stereochemistry; organic synthesis and reaction mechanism; heterocyclic compounds; organic molecules and materials for energy.

Module 3: Quantum mechanics; molecular spectroscopy; group theory and its applications; nanomaterials.

Module 4: Introduction to NMR spectroscopy and MRI; mass spectrometry and its applications.

Teachers/Research Scholars who wish to participate in this Refresher Course should submit their completed application form online to the following link

http://web-japps.ias.ac.in:8080/Refreshcourse/RCCD.jsp

A hard copy of the application through the Head of the institution should also be sent by speed post to: Prof. R. T.

Pardasani, Course Coordinator, Department of Chemistry, School of Chemical Sciences and Pharmacy, Central University of Rajasthan, Bandarsindri 305 817, Ajmer-Jaipur Express way, Ajmer Dist., Rajasthan. In the case of teacher applicants, a print copy of the application should be forwarded by the Head of the Institution stating that leave will be sanctioned if the applicant is selected for the Course. For any other query, applicants can send an e-mail to: hod.chem@curaj.ac.in

Last date for the receipt of online application: 15 October 2014.

Last date for the receipt of the printed copy of the online-submitted application form through proper channel: 30 October 2014.

Selected participants will be intimated through e-mail by 31 October 2014. The selected outstation participants will be provided with local hospitality and round-trip bus/train (3-tier AC) by the shortest route. 